\title{
Comparison of the HER2, estrogen and progesterone receptor expression profile of primary tumor, metastases and circulating tumor cells in metastatic breast cancer patients
}

Bahriye Aktas ${ }^{1 *}$, Sabine Kasimir-Bauer ${ }^{1}$, Volkmar Müller ${ }^{2}$, Wolfgang Janni ${ }^{3}$, Tanja Fehm ${ }^{4}$, Diethelm Wallwiener ${ }^{5}$, Klaus Pantel ${ }^{6}$, Mitra Tewes ${ }^{7}$ and on behalf of the DETECT Study Group

\begin{abstract}
Background: The expression of HER2, estrogen (ER) and progesterone (PR) receptor can change during the course of the disease in breast cancer (BC). Therefore, reassessment of these markers at the time of disease progression might help to optimize treatment decisions. In this context, characterization of circulating tumor cells (CTCs) could be of relevance since metastatic tissue may be difficult to obtain for repeated analysis. Here we compared HER2/ER/ PR expression profiles of primary tumors, metastases and CTCS.

Methods: Ninety-six patients with metastatic BC from seven University BC Centers in Germany were enrolled in this study. Blood was obtained at the time of first diagnosis of metastatic disease or disease progression and analyzed for CTCs using the Adnatest BreastCancer (QIAGEN Hannover GmbH, Germany) for the expression of EpCAM, MUC-1, HER2, ER and PR. HER2 expression on CTCs was additionally assessed by immunocytochemistry using the CellSearch ${ }^{\oplus}$ assay.

Results: The detection rate for CTCs using the AdnaTest was $43 \%$ (36/84 patients) with the expression rates of $50 \%$ for HER2 (18/36 patients), $19 \%$ for ER (7/36 patients) and $8 \%$ for PR (3/36 patients), respectively. Primary tumors and CTCs displayed a concordant HER2, ER and PR status in $59 \%(p=0.262), 39 \%(p=0.51)$ and $44 \%(p=0.62)$ of cases, respectively. For metastases and CTCs, the concordance values were $67 \%$ for HER2 $(p=0.04), 43 \%$ for ER $(p=0.16)$ and $46 \%$ for PR $(p=0.6)$. Using the CellSearch ${ }^{\circledast}$ assay, the CTC-positivity rate was $53 \%$ (42/79 patients) with HER2 expressed in $29 \%(12 / 42)$ of the patients. No significant concordance ( $58 \%$ and $53 \%$ ) was found when HER2 on CTCs was compared with HER2 on primary tumors $(p=0.24)$ and metastases $(p=0.34)$. Interestingly, primary tumors and metastases were highly concordant for HER2 $(84 \%, p=1.13 \mathrm{E}-$ 08), ER ( $90 \%, p=3.26 \mathrm{E}-10)$ and PR ( $83 \%, p=2.09 \mathrm{E}-09)$ and ER-and PR-positive metastases were significantly found to be of visceral origin ( $p=0.03, p=0.02)$.
\end{abstract}

Conclusion: Here we demonstrate that the molecular detection of HER2 overexpression in CTC is predictive of the HER2 status on metastases. Detailed analysis of ER and PR expression rates in tissue samples and CTCs may provide useful information for making treatment decisions.

Keywords: Metastatic breast cancer, Biopsy, Metastases, Receptor expression profile, CTC, Circulating tumor cells

\footnotetext{
*Correspondence: bahriye.aktas@uk-essen.de

'Department of Gynecology and Obstetrics, University of Duisburg-Essen,

Essen, Germany

Full list of author information is available at the end of the article
} 


\section{Background}

In primary and metastatic breast cancer (MBC), tumors are usually analyzed for the presence or absence of the estrogen receptor (ER), the progesterone receptor (PR), and for amplification of HER-2, and the results of these analyses direct the types of treatment that patients receive. In $\mathrm{MBC}$, patients may be treated with systemic therapy (chemotherapy, biological therapy, targeted therapy, hormonal therapy), local therapy (surgery, radiation therapy), or a combination of these treatments. The choice of treatment generally depends on the characteristics of the primary tumor because metastatic tissue is often difficult to obtain. Notably, HER-2 as well as ER/ PR were shown to be differentially expressed between the primary tumor and corresponding metastases in up to $48 \%$ which might lead to ineffective treatment in the absence of the respective marker [1-6]. Therefore, reassessment of these markers at the time of disease progression might help to optimize treatment decisions. Although biopsies from most metastatic sites may be obtained by the use of imaging and interventional radiology on a routine basis, these techniques are invasive and may pose some discomfort or may result in complications. Thus, a blood based biomarker would be desirable to bypass these problems.

In this regard, circulating tumor cells (CTCs) would be an ideal 'surrogate tissue' to identify prognostic and predictive factors that will help in selecting the optimal therapeutic strategy for each individual patient in case that metastatic tissue is not available.

Our study group has already demonstrated that ER and PR were differentially expressed between primary tumor and CTCs in MBC [7]. It was the purpose of the present study to compare the HER2/ER/PR expression profile of primary tumor and metastases, primary tumor and CTCs as well as metastases and CTCs. To our knowledge, it is the first study comparing histopathological and molecular findings between primary tumor, metastases and CTCs.

\section{Methods}

\section{Patients and study design}

A total of $96 \mathrm{MBC}$ cancer patients, from seven University Breast Cancer Centers [Essen $(n=62)$, Düsseldorf $(n=6)$, Erlangen $(n=3)$, Hamburg $(n=10)$, Heidelberg $(n=5)$, Muenchen $(n=3)$, Regensburg $(n=2)$ and Tuebingen $(n=5)]$ in Germany were enrolled in this prospective open non-randomized study from 12/2007 until 04/2009. In general, most patients (69 \%) had ductal breast cancer, moderately and poorly differentiated tumors were predominant. $73 \%$ of the primary tumors were ER-, $55 \%$ were PR-positive and $33 \%$ had an overexpression of HER2 (Dako score 3+). Biopsies of metastases were taken from visceral (63\%) and non- visceral sites (37\%). Patients received different chemotherapeutic treatments in different lines of metastatic settings including anthracyclines, taxanes, capecitabine, vinorelbine and 5-FU or endocrine treatment including Tamoxifen, aromatase inhibitors and Fulvestrant (data not shown). CTCs from these patients were analyzed for ER/PR/HER2 expression during palliative therapy to compare these results with receptor expression on the primary tumor and metastases.

\section{Eligibility criteria}

The eligibility criteria were as follows: Epithelial invasive carcinoma of the breast with distant metastatic disease (M1), age $\geq 18$ years, first diagnosis of metastatic disease or disease progression (before start of new treatment regimen). Prior adjuvant treatment, radiation or any other treatment of metastatic disease were permitted.

Exclusion criterion was secondary primary malignancy (except in situ carcinoma of the cervix or adequately treated basal cell carcinoma of the skin). Blood was drawn before the start of a new line of therapy. A webbased databank was designed for data management and online-documentation (www.detetct-study.de). All specimens were obtained after written informed consent and collected using protocols approved by the institutional review board (2007/B01).

\section{Enrichment and molecular characterization of CTCs using the AdnaTest BreastCancer Kits}

Two $5 \mathrm{ml}$ EDTA blood samples were collected for isolation of CTCs using the AdnaCollect blood collection tubes (QIAGEN Hannover GmbH, Langenhagen, Germany) and stored at $4{ }^{\circ} \mathrm{C}$ until further examination. In-house samples were processed immediately or not later than $4 \mathrm{~h}$ after blood withdrawal, shipped samples were processed within $24 \mathrm{~h}$. Establishment and validation of the AdnaTest BreastCancer assay has been described in detail elsewhere [7-9].

Briefly, all samples were subjected to immunomagnetic enrichment of CTCs using the AdnaTest BreastCancerSelect kit (QIAGEN Hannover GmbH, Langenhagen, Germany) followed by RNA isolation and subsequent gene expression analysis [EpCAM (GA733-2), MUC-1, HER2] by reverse transcription and Multiplex-PCR (polymerase chain reaction) in separated tumor cells using the The AdnaTest BreastCancerDetect (QIAGEN Hannover GmbH, Langenhagen, Germany) according to the instructions provided with the kit. Expression of ER and PR was assessed in an additional single-plex RT-PCR. Visualization of the PCR fragments was carried out with a 2100 Bioanalyzer using the DNA 1000 LabChips (Agilent Technologies) and the Expert Software Package (version B.02.03.SI307) both Böblingen, Germany. The primers generate fragments of the following sizes: GA 733-2: 395 
base pairs (bp), MUC1: 293 bp, HER2: 270 bp, PR: 270 bp, ER: 305 bp, and actin: $114 \mathrm{bp}$.

\section{Evaluation of data}

The test is considered positive if a PCR fragment of at least one tumor associated transcript (MUC-1, GA 7732 or HER2) is clearly detected. Peaks with a concentration of $>0.15 \mathrm{ng} / \mu \mathrm{l}$ are positive for the transcripts GA733-2, MUC1 and HER2. Peaks that are not detected at the above setting are negative (concentration of $<$ $0.15 \mathrm{ng} / \mu \mathrm{l})$. Peaks with a concentration of $>0.60 \mathrm{ng} / \mu \mathrm{l}$ are positive for the ER transcript and the PR expression is considered positive when the transcript is detected without applying any cut-off.

\section{Determination of HER2-expression using the CellSearch assay}

Two $7.5 \mathrm{ml}$ blood samples were collected into CellSave tubes (Veridex Inc.) for the CellSearch assay and sent at room temperature based on the manufacturer's recommendation. Blood samples not processed within $96 \mathrm{~h}$ for the CellSearch assay were discarded. A validation study demonstrated that the samples could be stored and transported (up to $72 \mathrm{~h}$ ) and showed high inter- and intra-assay concordance of the results in a multicenter setting [10].

In brief, CTCs are captured from peripheral blood by anti-EpCAM-antibody-bearing ferrofluid and identified by cytokeratin-positivity, negativity for the leukocyte common antigen CD45 and DAPI staining to ensure the integrity of the nucleus. HER2 expression of CTCs was characterized within the Cell Search system by addition of a FITC (Fluorescein isothiocyanate)-labeled anti-HER2 antibody (CellSearch $^{\odot}$ tumor phenotyping reagent HER2/neu, Veridex, Raritan, NJ) as described previously [11]. The intensity of the HER2-specific immunofluorescence was categorized as negative (0), weak $(1+)$, moderate $(2+)$ and strong $(3+)$. CTCs were considered HER2 positive if at least one CTC had a strong HER2 staining (3+).
Immunohistochemical analysis of the primary tumor and metastases

The ER, PR and HER2 status of the primary tumor was obtained from the patients' charts. In all participating centers, the HER2 status has been determined by the HERCEP $^{\text {sa }}$ test (Dako, Glostrup, Denmark) and/or the Pathvysion-kit (HER2/neu) (Vysis, Downers Grove, IL).

All pathology laboratories had participated in ring experiments and were certified laboratories for ER, PR and HER2 detection. A central review of the ER, PR and HER2 status of the primary tumor as well as the metastases was, therefore, not performed.

\section{Statistical analysis}

Concordance of the results between the different methods [AdnaTest (HER2;ER;PR), CellSearch (HER2) and tissue IHC for HER2, ER and PR] was evaluated using cross tabulation combined with Fisher's exact-test. The comparison of the primary tissue and the metastatic tissue phenotype with regards to HER2, ER and PR was analyzed accordingly. WinSTAT ${ }^{\circledR}$ for Microsoft ${ }^{\circ}$ Excel version 2012.1 (www.winstat.de) was used for the statistical calculations. Null hypothesis of discordant results was rejected when $p$-values were $\leq 0.05$.

\section{Results \\ Detection of CTCs}

The detection rate for CTCs as determined by the AdnaTest and the CellSearch assay are demonstrated in Fig. 1. The AdnaTest could be applied in 84/96 patients (88 \%) and resulted in an overall CTC detection rate of $43 \%(36 / 84$ patients) with the expression of $50 \%(18 / 36$ patients) for HER2 and EpCAM, $61 \%$ for MUC-1 (22/ 36 patients), $19 \%$ for ER (7/36 patients) and $8 \%$ for PR (3/36 patients), respectively. Applying the CellSearch ${ }^{\circ}$ assay for CTC detection in 79/96 (82\%) of patients, the CTC-positivity rate was $53 \%$ (42/79 patients) with the expression rate of $29 \%$ for HER2 (12/42 patients). Since the CellSearch system is based on immunomagnetic

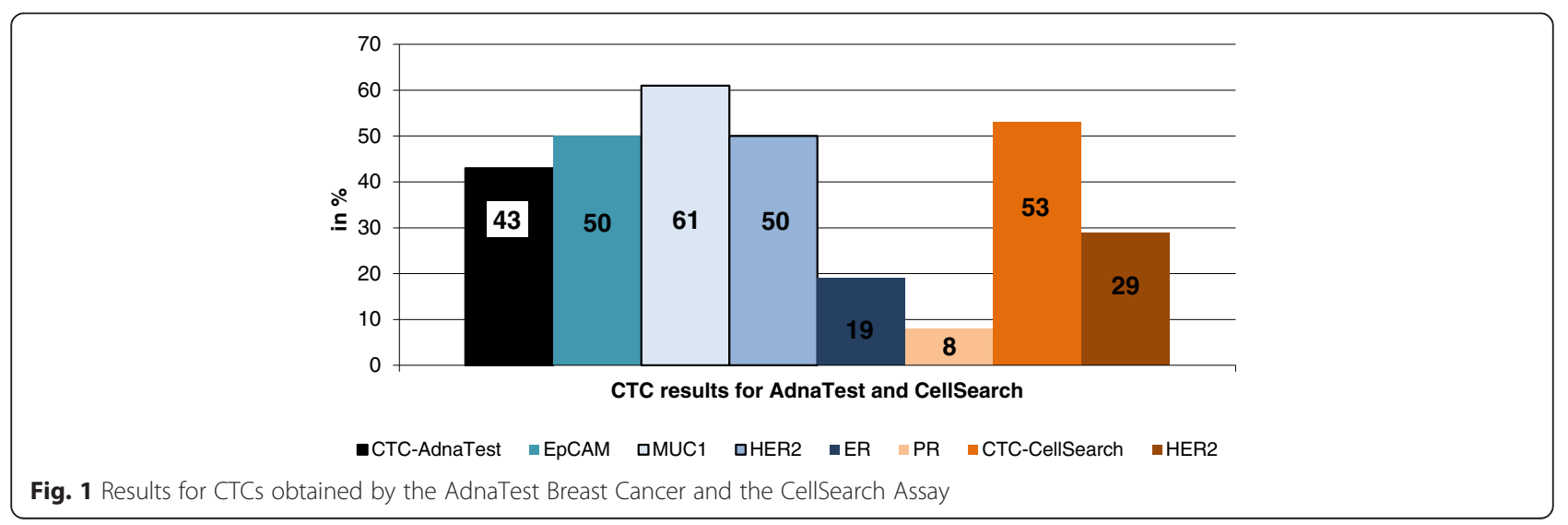


EpCAM capturing, a direct comparison of EpCAMpositive CTCs as detected by both test systems was performed. A comparison for EpCAM was feasible in 38 patients. The AdnaTest BreastCancer only detected 8 of 38 EpCAM-positive cases as evaluated by CellSearch. On the other hand, in the 37 CellSearch-negative cases, the AdnaTest detected 15 positive cases with the expression rates of $40 \%$ for EpCAM and HER2 (both 6/15 patients) and $76 \%$ for MUC-1 (11/15 patients), data not shown.

\section{Comparisons of expression profiles on CTCs with those on tissue samples}

Comparisons of the expression profiles of ER, PR and HER2 on CTCs with those on tissue samples were only performed in CTC-positive patients. A comparison for HER2 was done applying the CellSearch assay and the AdnaTest Breast Cancer. Due to technical requirements of both assays, a comparison of ER and PR was only feasible using the AdnaTest BreastCancer. All comparison studies are documented in Table 1.

Applying the AdnaTest BreastCancer, primary tumors and CTCs displayed a concordant HER2, ER and PR status in $59 \%(p=0.262), 39 \%(p=0.51)$ and $44 \%(p=0.62)$ of cases, respectively. For metastases and CTCs, the concordance values were $67 \%$ for HER2 $(p=0.04), 43 \%$ for ER $(p=0.16)$ and $46 \%$ for PR $(p=0.6)$. Interestingly, in 26/36 patients with ER/PR-positive metastases, CTCs were positive in $27 \%$ of cases and in the other $10 \mathrm{ER} / \mathrm{PR}$ negative patients, the concordance was $100 \%(p=0.066)$.

Applying the CellSearch ${ }^{\circ}$ assay, no significant concordance (58 \% and $53 \%$ ) was found when HER2 status on
CTCs was compared with HER2 expression on primary tumors $(p=0.41)$ and on metastases $(p=0.52)$.

Comparing the expression of the predictive markers on primary tumor and metastases, a high concordance was displayed for $\mathrm{ER}(90 \%, p=3.26 \mathrm{E}-10)$, PR $(83 \%, p=2.09 \mathrm{E}$ $09)$ and HER2 (84 \%, $p=1.13 \mathrm{E}-08)$. These results were confirmed when concordances for ER, PR and HER2 were only calculated in CTC-positive samples (ER: $p=7.2 \mathrm{E}-10$; PR: $p=6.23 \mathrm{E}-10$ and HER2: $p=0.001$ ).

\section{Direction of concordance/discordance in the expression of ER, PR and HER2}

As already described above, these analyses were only feasible using the results obtained with the AdnaTest Breast Cancer. As apparent from Table 2, a loss of receptor expression on CTCs can be seen for ER and PR when compared to the expression on primary tumors and on metastases. In contrast, although not significant, a trend for vice versa behaviour with regard to HER2 expression can be obtained for a substantial number of patients.

\section{Influence of the type of metastatic lesion on concordance} Table 3 illustrates the expression of predictive markers with regard to visceral (ML1) and bone (ML2) metastasis. Although not significant, visceral metastasis is more likely found in ER- as well as PR-positive tumors whereas no difference can be obtained for HER2. Interestingly, when these analyses were performed for metastases, ER- and PR-positive metastases significantly were

Table 1 Comparisons of expression profiles on CTCs with those on tissue samples

\begin{tabular}{|c|c|c|c|c|c|c|c|c|c|}
\hline & $\begin{array}{l}\text { Primary } \\
\text { Tumor }\end{array}$ & Metastases & $\begin{array}{l}p \text {-value } \\
\text { Concordance (C) }\end{array}$ & $\begin{array}{l}\text { Primary } \\
\text { Tumor }\end{array}$ & CTCs & $\begin{array}{l}p \text {-value } \\
\text { Concordance (C) }\end{array}$ & Metastases & CTCs & $\begin{array}{l}p \text {-value } \\
\text { Concordance }(C) \\
\end{array}$ \\
\hline Overall & 96 (100\%) & 96 (100%) & & 36 (100\%) & 36 (100 \%) & & 36 (100 \%) & $36(100 \%)$ & \\
\hline \multicolumn{10}{|l|}{ ER Status } \\
\hline $\begin{array}{l}\text { Negative } \\
\text { Positive } \\
\text { Unknown }\end{array}$ & $\begin{array}{l}25(26 \%) \\
70(73 \%) \\
1(1 \%)\end{array}$ & $\begin{array}{l}24(25 \%) \\
64(67 \%) \\
8(8 \%)\end{array}$ & $\begin{array}{l}P=3,26 \mathrm{E}-10 \\
C=90 \%\end{array}$ & $\begin{array}{l}11(31 \%) \\
25(69 \%) \\
0(0 \%)\end{array}$ & $\begin{array}{l}31(86 \%) \\
5(14 \%) \\
0(0 \%)\end{array}$ & $\begin{array}{l}P=0.51 \\
C=39 \%\end{array}$ & $\begin{array}{l}10(28 \%) \\
25(69 \%) \\
1(3 \%)\end{array}$ & $\begin{array}{l}31(86 \%) \\
5(14 \%) \\
0(0 \%)\end{array}$ & $\begin{array}{l}P=0.16 \\
C=43 \%\end{array}$ \\
\hline \multicolumn{10}{|l|}{ PR Status } \\
\hline $\begin{array}{l}\text { Negative } \\
\text { Positive } \\
\text { Unknown }\end{array}$ & $\begin{array}{l}42(44 \%) \\
53(55 \%) \\
1(1 \%)\end{array}$ & $\begin{array}{l}44(46 \%) \\
44(46 \%) \\
8(8 \%)\end{array}$ & & $\begin{array}{l}15(42 \%) \\
21(58 \%) \\
0(0 \%)\end{array}$ & $\begin{array}{l}33(92 \%) \\
3(8 \%) \\
0(0 \%)\end{array}$ & & $\begin{array}{l}15(28 \%) \\
20(69 \%) \\
1(3 \%)\end{array}$ & $\begin{array}{l}33(92 \%) \\
3(8 \%) \\
0(0 \%)\end{array}$ & \\
\hline & & & $P=2,09 \mathrm{E}-09$ & & & $\begin{array}{l}P=0.62 \\
C=44 \%\end{array}$ & & & $\begin{array}{l}P=0.6 \\
C=46 \%\end{array}$ \\
\hline & & & $C=83 \%$ & & & & & & \\
\hline \multicolumn{10}{|c|}{ HER 2 Status } \\
\hline \multirow[t]{2}{*}{$\begin{array}{l}\text { Negative } \\
\text { Positive } \\
\text { Unknown }\end{array}$} & $\begin{array}{l}55(57 \%) \\
32(33 \%) \\
9(10 \%)\end{array}$ & $\begin{array}{l}53(55 \%) \\
38(40 \%) \\
5(5 \%)\end{array}$ & & $\begin{array}{l}20(55 \%) \\
14(39 \%) \\
2(6 \%)\end{array}$ & $\begin{array}{l}18(50 \%) \\
18(50 \%) \\
0(0 \%)\end{array}$ & $\begin{array}{l}\text { AdnaTest } \\
P=0.26 \\
C=59 \% \\
\text { Cellsearch }\end{array}$ & $\begin{array}{l}22(61 \%) \\
14(39 \%) \\
0(0 \%)\end{array}$ & $\begin{array}{l}18(50 \%) \\
18(50 \%) \\
0(0 \%)\end{array}$ & $\begin{array}{l}\text { AdnaTest } \\
P=0.0429 \\
C=67 \% \\
\text { Cellsearch }\end{array}$ \\
\hline & & & $\begin{array}{l}P=1,13 \mathrm{E}-08 \\
C=84 \%\end{array}$ & & & $\begin{array}{l}P=0,41 \\
C=58 \%\end{array}$ & & & $\begin{array}{l}P=0,52 \\
C=53 \%\end{array}$ \\
\hline
\end{tabular}


Table 2 Direction of the concordance/discordance in the expression of ER, PR and HER2

\begin{tabular}{|c|c|c|c|}
\hline \multirow[t]{12}{*}{ a) $E R$} & & Tumor ER- & Tumor ER+ \\
\hline & AdnaTest ER- & 10 & 21 \\
\hline & AdnaTest ER+ & 1 & 4 \\
\hline & & \multicolumn{2}{|c|}{ Fishers exact Test: $p=0,51$} \\
\hline & & Metastases ER- & Metastases ER+ \\
\hline & AdnaTest ER- & 10 & 20 \\
\hline & AdnaTest ER+ & 0 & 5 \\
\hline & & \multicolumn{2}{|c|}{ Fishers exact Test: $p=0,16$} \\
\hline & & Metastases ER- & Metastases ER+ \\
\hline & Tumor ER- & 9 & 19 \\
\hline & Tumor ER+ & 1 & 2 \\
\hline & & \multicolumn{2}{|c|}{ Fishers exact Test: $p=7,2 \mathrm{E}-6$} \\
\hline \multirow[t]{12}{*}{ b) $P R$} & & Tumor PR- & Tumor PR+ \\
\hline & AdnaTest PR- & 14 & 19 \\
\hline & AdnaTest PR+ & 1 & 2 \\
\hline & & \multicolumn{2}{|c|}{ Fishers exact Test: $p=0,62$} \\
\hline & & Metastases PR- & Metastases PR+ \\
\hline & AdnaTest PR- & 14 & 18 \\
\hline & AdnaTest PR+ & 1 & 2 \\
\hline & & \multicolumn{2}{|c|}{ Fishers exact Test: $p=0,60$} \\
\hline & & Metastases PR- & Metastases PR+ \\
\hline & Tumor PR- & 13 & 2 \\
\hline & Tumor PR+ & 2 & 18 \\
\hline & & \multicolumn{2}{|c|}{ Fishers exact Test: $p=6,23 \mathrm{E}-6$} \\
\hline \multirow[t]{11}{*}{ c) HER2 } & & Tumor HER2- & Tumor HER2+ \\
\hline & AdnaTest HER2- & 12 & 6 \\
\hline & AdnaTest HER2+ & 8 & 8 \\
\hline & & \multicolumn{2}{|c|}{ Fishers exact Test: $p=0,043$} \\
\hline & & Metastases HER2- & Metastases HER2+ \\
\hline & AdnaTest HER2- & 14 & 4 \\
\hline & AdnaTest HER2+ & 8 & 10 \\
\hline & & \multicolumn{2}{|c|}{ Fishers exact Test: $p=0,043$} \\
\hline & & Metastases HER2- & Metastases HER2+ \\
\hline & Tumor HER2- & 17 & 3 \\
\hline & Tumor HER2+ & 4 & 10 \\
\hline
\end{tabular}

found to be of visceral origin $(p=0.03 ; p=0.02)$ whereas no trend was seen for HER2.

\section{Discussion}

In $\mathrm{MBC}$, the choice of therapy generally depends on the size, location, and number of metastatic sites whereas the decision to administer antihormonal- and/or HER2-
Table 3 Expression of predictive markers on primary tumor and metastases with regard to visceral (ML1) and bone (ML2) metastasis

\begin{tabular}{|c|c|c|}
\hline & ML1 & ML2 \\
\hline Tumor ER- & 6 & 8 \\
\hline \multirow[t]{3}{*}{ Tumor ER+ } & 32 & 15 \\
\hline & \multicolumn{2}{|c|}{ Fischers exact Test: $p=0,08$} \\
\hline & ML1 & ML2 \\
\hline Tumor PR- & 13 & 13 \\
\hline \multirow[t]{3}{*}{ Tumor PR+ } & 25 & 10 \\
\hline & \multicolumn{2}{|c|}{ Fishers exact Test: $p=0,08$} \\
\hline & ML1 & ML2 \\
\hline Tumor Her2- & 22 & 15 \\
\hline \multirow[t]{3}{*}{ Tumor Her2+ } & 11 & 7 \\
\hline & \multicolumn{2}{|c|}{ Fishers exact Test: $p=0,9$} \\
\hline & ML1 & ML2 \\
\hline Metastases ER- & 6 & 9 \\
\hline \multirow[t]{3}{*}{ Metastases ER+ } & 33 & 14 \\
\hline & \multicolumn{2}{|c|}{ Fishers exact Test: $p=0,03$} \\
\hline & ML1 & ML2 \\
\hline Metastases PR- & 16 & 16 \\
\hline \multirow[t]{3}{*}{ Metastases PR+ } & 23 & 7 \\
\hline & \multicolumn{2}{|c|}{ Fishers exact Test: $p=0,02$} \\
\hline & ML1 & ML2 \\
\hline Metastases Her2- & 23 & 16 \\
\hline \multirow[t]{2}{*}{ Metastases Her2+ } & 16 & 7 \\
\hline & \multicolumn{2}{|c|}{ Fishers exact Test: $p=0,4$} \\
\hline
\end{tabular}

targeted therapy depends on the expression of these markers on the primary tumor since metastatic tissue is often difficult to obtain. However, several BC studies have indicated that the expression of HER2, ER and PR can change during course of disease [1-6, 12-30]. Therefore, reassessment of the predictive markers at the time of disease progression might help to optimize treatment decisions. In this context, characterization of CTCs could be of relevance in the future.

Here we demonstrate that the molecular detection of HER2 overexpression in CTCs using the AdnaTest BreastCancer is able to significantly predict the HER2 status on metastases. However, for ER/PR, a more detailed analysis of expression rates in tissue samples will be necessary to decide whether to use CTCs as a useful tool for treatment decisions. Interestingly, in contrast to some already published studies $[1-6,12-30]$, we could show that primary tumors and their metastases showed a highly significant concordance of the expression of predictive markers. Furthermore, ER- and PR-positive metastases significantly were found to be of visceral origin whereas no trend was seen for HER2 which has to be discussed in more detail. 
In a prospective study, Simmons et al. demonstrated a discordant ER/PR and HER2 status in $40 \%$ and $8 \%$ of cases in more than half of the 40 patients analyzed who presented with new lesions suspicious for MBC. Consequently, therapeutic intervention was changed accordingly in $20 \%$ of the patients who agreed to undergo biopsy not only to confirm their metastatic phenotype but also to have reassurance of receiving "targeted therapy" [3]. Another MBC study including 25 patients with liver metastases observed a discordant ER, PR and HER2 receptor status in $14.5 \%$, $48.6 \%$ and $13.9 \%$ of cases, respectively, which led to change in therapy in $12.1 \%$ of patients [2]. With regard to HER2, subsequently published studies have reported discordant rates from $1 \%$ to $24 \%$ between primary tumor and metastases [1, 2, 12-29] and a study-level meta-analysis including 26 trials and about 2.500 patients, found a discordance rate for either HER2 loss or gain of $5.5 \%$ [30, 31]. These findings are quite in opposite to our study, showing a significantly high concordance for these markers when comparing primary tumor and metastases.

A discordant expression of these receptors and the primary tumor and corresponding metastases and/or CTCs has already been demonstrated with a discordance between primary $\mathrm{BC}$ and HER2 expression on CTCs in the setting of disease recurrence at variable rates, with a gain of HER2 from $9 \%$ to over $60 \%$ in different studies [32-39]. The fact that ER and PR were differentially expressed between primary tumor and CTCs confirms the results of our previously published study demonstrating a loss of receptor expression on CTCs when compared with the expression on primary tumors [7]. These results can now be extended and confirmed for metastases and CTCs. However, the concordance for biomarker negativity seems to be higher in this study, although the number of these cases is quite small. In fact, the possibility of changes in receptor status during the course of tumor progression in triple-negative $\mathrm{BC}$ is very low, up to $8 \%$, despite changes in receptor positive BC with up to $40 \%$ [40]. One could speculate that escape from antitumor therapy is more effective for CTCs when losing ER and PR on the surface.

In addition, the fact that ER- and PR-positive metastases significantly were found to be of visceral origin with a positive trend also documented in primary disease allows the hypothesis that CTC release as well as their downregulation of hormonal receptors might be recognized as a resistance mechanism to adjuvant endocrine therapy. As a consequence, CTCs released under therapy downregulate the therapeutic target during their phase of epithelial-mesenchymal transition (EMT) but recover ER/PR overexpression during the course of metastasis. This could fairly explain how hormone receptor positive visceral metastasis appear in significant concordance to the metastatic hormonal phenotype but also still seem to be positively correlated with the primary lesion. These results were not found for non-visceral metastases and we can only speculate that probably the different environment might influence the rate of receptor expression.

In our study, applying the AdnaTest BreastCancer, metastases and CTCs displayed a significantly concordant HER2 status in $67 \%$ of cases whereas no significant concordance values could be shown for ER and PR. In contrast, applying the CellSearch ${ }^{\circledast}$ assay, no significant concordance was found when HER2 status on CTCs was compared to primary tumors and metastases. These findings might be explained by the different selection strategies of both assays. CellSearch ${ }^{\circ}$ as an EpCAM-dependent assay might not detect CTCs that lost the EpCAM epitope and, therefore might result in false negatives with regards to HER2 overexpressing cells [41]. In contrast, the AdnaTest CTC enrichment method consists of an antibody mixture targeting EpCAM and MUC1, which might enable efficient CTC enrichment even in case EpCAM got lost.

However, CTCs are highly heterogeneous and using EpCAM-based capturing methods, it has been shown that this procedure is not able to detect the entire, highly heterogenous population of CTCs in MBC. In this regard, it has been demonstrated that these methods underestimate the most important subpopulations of CTCs involved in cancer dissemination, which often share EMT and stemness features [42-45]. In the current study, these subpopulations have not been analyzed which might explain discordant findings. Thus, despite the prognostic impact of CTC counts, molecular methods might complement these studies by improving the overall detection rate as well as sensitivity and, thus, permitting the assessment of genomic markers in CTCs of MBC patients as recently published [46].

From the clinical point of view, in a recent review of the literature, Turner and Di Leo concluded that the best management approach for receptor discordance between primary and metastatic disease is currently unknown, and the very limited evidence of alteration in clinical outcomes based on repeated biopsy does not seem to be strong enough to confirm that repeated biopsy is essential in every patient [47].

However, although these discrepancies have been demonstrated, the acquisition of tissue from metastases is not recommended as routine practice in any guideline. Thus, monitoring and phenotypic characterization of CTCs can provide new insights into the clonal selection of tumor cells under palliative therapies which may allow physicians to follow cancer changes over time and tailor treatment accordingly.

\section{Conclusion}

To the best of our knowledge, this is the first study comparing HER2/ER/PR expression profiles of primary tumors, metastases and CTCs. Although we could show that primary tumors and their metastases showed a highly 
significant concordance of the expression of predictive markers, monitoring and a more comprehensive phenotypic characterization of CTCs will show whether CTCs can provide new insights into the clonal selection of resistant tumor cells under biological therapies. In this regard, the DETECT III phase III trial in Germany, comparing standard therapy alone versus standard therapy plus HER2 targeted therapy in patients with initially HER2-negative MBC and HER2-positive CTCs will probably answer that question. In this setting, patients with HER2-positive CTCs receive a targeted treatment option, noting that CTC detection and HER2 testing is performed by use of the CellSearch $^{\circledast}$ assay (www.detetct-studien.de).

\section{Acknowledgement}

We gratefully thank the patients for their willingness to participate in the study. The authors highly valuate the assistance of Julia Scholz from the Department of Internal Medicine (Cancer Research) for organizational functions, clinical documentation, blood drawing. We further thank the Research Laboratory, the medical and nursing team of the Department of Gynecology and Obstetrics for their collaboration in sample collection and preparatory operation.

\section{Funding}

This study was supported by research resources of the study group.

\section{Availability of data and materials}

The data that support the findings of this study are available from DETECT Study Group but restrictions apply to the availability of these data, which were used under license for the current study, and so are not publicly available. Data are however available from the authors upon reasonable request and with permission of the DETECT Study Group.

\section{Authors' contributions \\ BA participated in conception of the study, recruited patients and drafted the paper. SKB carried out the AdnaTest and drafted the paper. VM recruited patients and revised the paper critically. WJ recruited patients and revised the paper critically. TF participated in conception of the study, did interpretation of the results. DW revised the paper critically. KP took care of the CEllSearch assays and revised the manuscript carefully. MT participated in conception of the study, recruited patients, took care of the detailed medical documentation and revised the paper carefully. All authors read and approved the final manuscript.}

\section{Competing interests}

Sabine Kasimir-Bauer is consultant of Qiagen Hannover GmbH Germany. All other authors declare that they have no competing interests.

\section{Consent for publication}

Not applicable.

\section{Ethics approval and consent to participate}

All patients gave their informed consent for the use of their blood samples. A web based databank was designed for data management and online documentation. All specimens were obtained after written informed consent and collected using protocols approved by the institutional review board (2007/B01).

\footnotetext{
Author details

${ }^{1}$ Department of Gynecology and Obstetrics, University of Duisburg-Essen, Essen, Germany. ${ }^{2}$ Department of Gynecology and Obstetrics, University Hospital Hamburg-Eppendorf, Hamburg, Germany. ${ }^{3}$ Department of Gynecology and Obstetrics, University Hospital UIm, Ulm, Germany. ${ }^{4}$ Department of Gynecology and Obstetrics, University Hospital Duesseldorf, Duesseldorf, Germany. ${ }^{5}$ Department of Gynecology and Obstetrics, University Hospital Tuebingen, Tuebingen, Germany. Institut of Tumor Biology, Center of Experimental Medicine, University Hospital Hamburg-Eppendorf, Hamburg, Germany. ${ }^{7}$ Department of Internal Medicine (Cancer Research), University Hospital Essen, Essen, Germany.
}

Received: 3 August 2015 Accepted: 20 July 2016

Published online: 25 July 2016

\section{References}

1. Amir E, Miller N, Geddie W, et al. Prospective Study Evaluating the Impact of Tissue Confirmation of Metastatic Disease in Patients With Breast Cancer. JCO. 2012;30(6):587-92.

2. Curigliano G, Bagnardi V, Viale G, et al. Should liver metastases of breast cancer be biopsied to improve treatment choice? Ann Oncol. 2011; 22(10):2227-33

3. Simmons C, Miller N, Geddie W et al. Does confirmatory tumor biopsy alter the management of breast cancer patients with distant metastases? Ann Oncol 2009:mdp028.

4. Regitnig $P$, Schippinger $W$, Lindbauer $M$, et al. Change of HER-2/neu status in a subset of distant metastases from breast carcinomas. J Pathol. 2004;203(4):918-26.

5. Amir E, Clemons M, Purdie CA, et al. Tissue confirmation of disease recurrence in breast cancer patients: Pooled analysis of multi-centre, multidisciplinary prospective studies. Cancer Treat Rev. 2012;38(6):708-14.

6. Locatelli MA, Curigliano G, Fumagalli L. Should liver metastases of breast cancer be biopsied to improve treatment choice. J Clinical Oncology 2010; CRA1008.

7. Aktas B, Müller V, Tewes $M$, et al. Comparison of estrogen and progesterone receptor status of circulating tumor cells and the primary tumor in metastatic breast cancer patients. Gynecol Oncol. 2011;122(2):356-60.

8. Hauch S, Zimmermann S, Lankiewicz S, et al. The Clinical Significance of Circulating Tumour Cells in Breast Cancer and Colorectal Cancer Patients. Anticancer Res. 2007;27(3A):1337-41.

9. Fehm T, Hoffmann O, Aktas B, et al. Detection and characterization of circulating tumor cells in blood of primary breast cancer patients by RT-PCR and comparison to status of bone marrow disseminated cells. Breast Cancer Res. 2009;11:R59.

10. Riethdorf S, Fritsche H, Müller V, et al. Detection of Circulating Tumor Cells in Peripheral Blood of Patients with Metastatic Breast Cancer: A Validation Study of the Cell Search System. Clin Cancer Res. 2007;13(3):920-8.

11. Riethdorf $S$, Müller $V$, Zhang $L$, et al. Detection and HER2 Expression of Circulating Tumor Cells: Prospective Monitoring in Breast Cancer Patients Treated in the Neoadjuvant GeparQuattro Trial. Clin Cancer Res. 2010;16(9):2634-45.

12. Botteri E, Disalvatore D, Curigliano G, et al. Biopsy of liver metastasis for women with breast cancer: Impact on survival. Breast. 2012:21(3):284-8.

13. Bogina $G$, Bortesi $L$, Marconi $M$, et al. Comparison of hormonal receptor and HER-2 status between breast primary tumours and relapsing tumours: clinical implications of progesterone receptor loss. Virchows Arch. 2011;459(1):1-10.

14. Chang HJ, Han S-W, Oh D-Y, et al. Discordant Human Epidermal Growth Factor Receptor 2 and Hormone Receptor Status in Primary and Metastatic Breast Cancer and Response to Trastuzumab. Jpn J Clin Oncol. 2011;41(5):593-9.

15. Dieci MV, Barbieri E, Piacentini F et al. Discordance in receptor status between primary and recurrent breast cancer has a prognostic impact: a single-Institution analysis. Ann Oncol 2012:mds248.

16. Fabi A, Di Benedetto A, Metro G, et al. HER2 Protein and Gene Variation between Primary and Metastatic Breast Cancer: Significance and Impact on Patient Care. Clin Cancer Res. 2011;17(7):2055-64.

17. Duchnowska R, Dziadziuszko R. Conversion of epidermal growth factor receptor 2 and hormone receptor expression in breast cancer metastases to the brain. Breast Cancer Res. 2012;14:R119.

18. Hoefnagel LD, van de Vijver MJ. Receptor conversion in distant breast cancer metastases. Breast Cancer Res. 2010;12:R75.

19. Jensen JD, Knoop A, Ewertz M, Laenkholm A-V. ER, HER2, and TOP2A expression in primary tumor, synchronous axillary nodes, and asynchronous metastases in breast cancer. Breast Cancer Res Treat. 2012;132(2):511-21.

20. Lindström LS, Karlsson E, Wilking UM et al. Clinically Used Breast Cancer Markers Such as Estrogen Receptor, Progesterone Receptor, and Human Epidermal Growth Factor Receptor 2 Are Unstable Throughout Tumor Progression. JCO 2012: JCO.2011.37.2482.

21. Macfarlane R, Seal M, Speers C, et al. Molecular Alterations Between the Primary Breast Cancer and the Subsequent Locoregional/Metastatic Tumor. Oncologist. 2012;17(2):172-8. 
22. Nishimura R, Osako T, Okumura Y. Changes in the ER, PgR, HER2, p53 and Ki-67 biological markers between primary and recurrent breast cancer: discordance rates and prognosis. World J Surgical Oncology. 2011;9:131.

23. Niikura N, Liu J, Hayashi N, et al. Loss of Human Epidermal Growth Factor Receptor 2 (HER2) Expression in Metastatic Sites of HER2-Overexpressing Primary Breast Tumors. JCO. 2012;30(6):593-9.

24. Sari E, Guler G, Hayran M, et al. Comparative study of the immunohistochemical detection of hormone receptor status and HER-2 expression in primary and paired recurrent/metastatic lesions of patients with breast cancer. Med Oncol. 2011;28(1):57-63.

25. St Romain P, Madan R, Tawfik OW, et al. Organotropism and prognostic marker discordance in distant metastases of breast carcinoma: fact or fiction? A clinicopathologic analysis. Hum Pathol. 2012;43(3):398-404.

26. Wilking U, Karlsson E, Skoog L, et al. HER2 status in a population-derived breast cancer cohort: discordances during tumor progression. Breast Cancer Res Treat. 2011;125(2):553-61.

27. Thompson AM, Jordan LB, Quinlan P, et al. Prospective comparison of switches in biomarker status between primary and recurrent breast cancer: the Breast Recurrence In Tissues Study (BRITS). Breast Cancer Res. 2010;12(6):R92.

28. Xiao C, Gong Y, Han EY, et al. Stability of HER2-positive status in breast carcinoma: a comparison between primary and paired metastatic tumors with regard to the possible impact of intervening trastuzumab treatment. Ann Oncol. 2011;22(7):1547-53.

29. Montagna E, Bagnardi V, Rotmensz $\mathrm{N}$ et al. Breast cancer subtypes and outcome after local and regional relapse. Ann Oncol 2011:mdr129.

30. Houssami N, Macaskill P, Balleine RL, et al. HER2 discordance between primary breast cancer and its paired metastasis: tumor biology or test artefact? Insights through meta-analysis. Breast Cancer Res Treat. 2011;129(3):659-74.

31. Curtit E, Nerich V, Mansi L, et al. Discordances in estrogen receptor status, progesterone receptor status, and HER2 status between primary breast cancer and metastasis. Oncologist. 2013;18(6):667-74.

32. Meng S, Tripathy D, Shete $\mathrm{S}$, et al. HER-2 gene amplification can be acquired as breast cancer progresses. Proc Natl Acad Sci U S A. 2004; 101(25):9393-8.

33. Pestrin M, Bessi S, Galardi F, et al. Correlation of HER2 status between primary tumors and corresponding circulating tumor cells in advanced breast cancer patients. Breast Cancer Res Treat. 2009;118(3):523-30.

34. Ignatiadis M, Rothé F, Chaboteaux C, et al. HER2-Positive Circulating Tumor Cells in Breast Cancer. PLoS One. 2011;6(1), e15624.

35. Flores LM, Kindelberger DW, Ligon AH, et al. Improving the yield of circulating tumour cells facilitates molecular characterisation and recognition of discordant HER2 amplification in breast cancer. $\mathrm{Br} \mathrm{J}$ Cancer. 2010;102(10):1495-502.

36. de Albuquerque A, Kaul S, Breier G, et al. Multimarker Analysis of Circulating Tumor Cells in Peripheral Blood of Metastatic Breast Cancer Patients: A Step Forward in Personalized Medicine. Breast Care. 2012;7(1):7-12.

37. Fehm T, Becker S, Duerr-Stoerzer $\mathrm{S}$, et al. Determination of HER2 status using both serum HER2 levels and circulating tumor cells in patients with recurrent breast cancer whose primary tumor was HER2 negative or of unknown HER2 status. Breast Cancer Res. 2007;9:R74

38. Ligthart ST, Bidard FC, Decraene C, et al. Unbiased quantitative assessment of Her-2 expression of circulating tumor cells in patients with metastatic and non-metastatic breast cancer. Ann Oncol. 2013;24:1231-8.

39. Turner N, Pestrin M, Galardi F, et al. Can Biomarker Assessment on Circulating Tumor Cells Help Direct Therapy in Metastatic Breast Cancer? Cancers. 2014; 6(2):684-707.

40. Karlsson $\mathrm{E}$, Lindström $\mathrm{LS}$, Wilking $\mathrm{U}$ et al. Discordance in hormone receptor status in breast cancer during tumor progression. J Clin Oncol 28:15 s, 2010 (suppl; abstr 1009)

41. Sieuwerts AM, Kraan J, Bolt J, et al. Anti-Epithelial Cell Adhesion Molecule Antibodies and the Detection of Circulating Normal-Like Breast Tumor Cells. JNCI J Natl Cancer Inst. 2009:101(1):61-6.

42. Aktas B, Tewes M, Fehm T, et al. Stem cell and epithelial-mesenchymal transition markers are frequently expressed in metastatic breast cancer patients with circulating tumor cells. Breast Cancer Res. 2009;11(4):R46.

43. Mego M, De Giorgi U, Dawood S, et al. Characterization of metastatic breast cancer patients with nondetectable circulating tumor cells. Int J Cancer. 2010;20:S1097-0215.

44. Raimondi C, Gradilone A, Naso G, et al. Epithelial-mesenchymal transition and stemness features in circulating tumor cells from breast cancer patients. Breast Cancer Res Treat. 2011;5:S1573-7217.
45. Krawczyk N, Meier-Stiegen F, Banys M et al. Expression of stem cell and epithelial-mesenchymal transition markers in circulating tumor cells of breast cancer patients. Biomed Res Int. 2014; doi: 10.1155/2014/415721.

46. Andreopoulou E, Yang LY, Rangel KM, et al. Comparison of assay methods for detection of circulating tumor cells (CTCS) in metastatic breast cancer (MBC): AdnaGen AdnaTest BreastCancer Select/Detect(cent) versus Veridex Cell Search(cent) system. Int J Cancer. 2011;5:S1097-0215.

47. Turner NH, Di Leo A. HER2 discordance between primary and metastatic breast cancer: Assessing the clinical impact. Cancer Treat Rev. 2013;39(8):947-57.

\section{Submit your next manuscript to BioMed Central and we will help you at every step:}

- We accept pre-submission inquiries

- Our selector tool helps you to find the most relevant journal

- We provide round the clock customer support

- Convenient online submission

- Thorough peer review

- Inclusion in PubMed and all major indexing services

- Maximum visibility for your research

Submit your manuscript at www.biomedcentral.com/submit
) Biomed Central 